\title{
Gill parasites of Cephalopholis argus (Teleostei: Serranidae) from Moorea (French Polynesia): site selection and coexistence
}

\author{
Cédrik M. Lo ${ }^{1,2}$ and Serge Morand ${ }^{3}$ \\ ${ }^{1}$ Ecole Pratique des Hautes Etudes (URA 1453), Université de Perpignan, Av. de Villeneuve, 66860 Perpignan Cedex, France; \\ ${ }^{2}$ Centre de Recherches Insulaires et Observatoires de l'Environnement (CRIOBE), B.P. 1013, Papetoai Moorea, Polynesie \\ Française; \\ ${ }^{3}$ Laboratoire de Biologie Animale (UMR C.N.R.S. 5555), Centre de Biologie et d'Ecologie Tropicale et Méditerranéenne, \\ Université de Perpignan, Av. de Villeneuve, 66860 Perpignan Cedex, France
}

Key words: ectoparasites, Cephalopholis argus, French Polynesia, coral reef fish, microhabitat, spatial distribution, parasite interactions

\begin{abstract}
The distribution and coexistence of gill ectoparasites of 121 specimens of Cephalopholis argus Bloch et Schneider, caught between October 1994 and October 1995, were investigated. Adults of the monogenean Benedenia sp. and copepod Hatschekia sp., the larval caligid copepod Caligus sp. (copepodite and chalimus stages), and praniza larvae of the isopod Gnathia sp. were found. All species were aggregated within the host population. Infracommunities were poor, with only $40.5 \%$ of fish infected by two parasite species. Only two individual fish harboured all the parasite species observed at the component community level. Prevalences were less than 50\% and mean intensities were low (less than 6 parasites/host). No dominant parasite species were observed in the host population. The spatial distribution of each parasite species was studied on different partitions of the gill arches. Adult parasite stages that are mobile showed much overlap in their distribution, whereas temporarily attached larvae of Caligidae were more site specific. Copepodite and chalimus larvae showed niche restriction that is probably due to gregarious behaviour. Positive associations between caligid larvae reflected intraspecific interaction for site and/or resources. Each of the Caligus sp. larval stages prefers specific sites, as do the adults, which occur exclusively in the buccal cavity of the host. Infracommunities were too poor and too few to induce processes of interspecific competition.
\end{abstract}

Studies on parasites of coral reef fish remain scarce although it has been demonstrated that ectoparasite diversity is high in the tropics (Rohde 1976, 1978a, b, Rohde and Heap 1998). Investigations on coral reef fish parasites of oceanic islands in the southern Pacific are rare and only recently have studies been conducted in French Polynesia (Rigby and Dufour 1996, Rigby and Adamson 1997, Rigby and Font 1997, Rigby et al. 1997, 1998, 1999, Lo 1998, Lo et al. 1998). Marine fishes are useful models to investigate questions dealing with ecology of parasite community structure (Rohde 1989, 1993, Holmes 1990, Morand et al. 1999). Gill ectoparasites are increasingly used to investigate the evolutionary significance of extrinsic or intrinsic factors of niche restriction such as intra- or interspecific competi-tion, reinforcement of reproductive barriers and en-hancement of the chance to mate (Rohde 1977, 1979, 1980, 1989, 1994, Ramasamy et al. 1985, Koskivaara et al. 1992, Rohde et al. 1994, Sharples and Evans 1995, Lo and Morand 2000). In a recent paper, Geets et al. (1997), following Rohde's hypothesis (1991), suggested that interspecific competition be of secondary importance for microhabitat choice whereas intraspecific factors such as mating process and reinforcement of reproductive barriers affect exploitation of gill-space by parasites. In the case of ectoparasitic crustaceans, Kabata (1981) stressed the importance of a set of morphological and physiological factors acting on site selection. To improve the analysis of gill microhabitats used by parasites, we arbitrarily partition gill arches into different zones and sectors as done previously by some authors (Lambert and Maillard 1974, Rohde 1976, 1977, Hanek and Fernando 1978, Noisy 1978, Ramasamy et al. 1985, Lo and Morand 2000).

Our aim in the present study is to describe the spatial distribution of ectoparasites on the gills of Cephalopholis argus Bloch et Schneider, an abundant fish on coral reefs of French Polynesia. We also attempt to evaluate what factors are involved in site selection for the gill parasites of this host.

\section{MATERIALS AND METHODS}

Specimens of Cephalopholis argus were caught monthly by spear fishing between October 1994 and October 1995 at

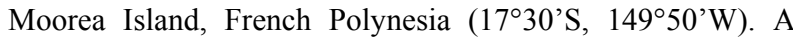
total of 121 fish were sampled on the outer slope of Tiahura (on the north-west coast of the island) with a monthly sample size of approximately 10 fish. Live fish were placed in aquaria before dissection within one hour after collection, whereas dead fish were frozen immediately for later examination. 
Non-mobile parasites such as chalimus and copepodites remained attached long after host death. Specimens of Hatschekia also remained attached to the gills and were seen to not detach easily from gills during manipulation under the microscope. Specimens of Benedenia were also attached to gills and it was quite difficult to remove these parasites from the gills. However, they can move actively and their spatial distribution reflects their mobile capacity. Finally, only specimens of Gnathia sp. can easily detach from fish. The stress imposed to fish by capture may influence the intensity of infection but not the spatial distribution.

Each host was measured (total length [TL] in centimetres) and weighed before dissection. Sex was determined and pairs of otoliths removed for age determination. Fishes were decerebrated without bloodshed and the left and right gill arches were excised, separated, and placed in a Petri dish containing seawater. Gill arches were examined (left arches first) using a dissecting microscope. Left and right arches were numbered 1 to 4 , gill arch 1 nearest the operculum and gill arch 4 nearest the midline (transverse partitioning); each gill arch was divided into four approximately equal regions dorsoventrally (sectors I, II, III, IV: longitudinal partitioning); the gill filaments were divided equally into three zones: proximal, middle and distal (vertical partitioning) (Fig. 1). Thus, 12 sections were defined as the smallest identifiable territorial units that can contain members of the parasite community. The 4 gill arches on one side of a fish represent 96 sections, with 12 sections per hemibranch. The bony part of the gill arch was also divided in four sectors. The available habitat of each gill arch was estimated by counting the number of gill filaments on each of the four gill arches for six fish. Parasites were counted and localised on each section of each arch. Careful attention was paid to separate different stages of copepod life cycles. For identification purposes, monogeneans were examined alive on a slide using a compound microscope or fixed with a drop of ammonium picrate-glycerine mixture on a slide, following the method of Malmberg (1957). Ectoparasitic crustaceans were fixed in alcohol and transferred to glycerin (Berlese's solution). Prevalence, intensity, mean intensity and other parasitological terms were used as defined by Bush et al. (1997).

Data were normalised with $\log (x+1)$ transformation to satisfy homoscedasticity or linearity necessary to perform parametric tests. The differences in intensity between left and right gill arches for each infracommunity were tested using Student's $t$-test. Data on intensity of infection of the four gill arches were summed for each monthly host sample. ANOVA and multiple comparisons were used to compare infection levels between gill arches, sectors and zones.

Several coefficients were performed for measuring association of ectoparasites by pairs in the component community of C. argus. Dice's coefficient measured the degree of association and Forbes' index and phi coefficient measured the amount of association deviation from expectation. Chisquare $\left(\mathrm{X}^{2}\right)$ test with Yates correction for continuity (Yates 1934) were used to determine the degree of significant association. All $p$ values less than $5 \%$ were considered significant.

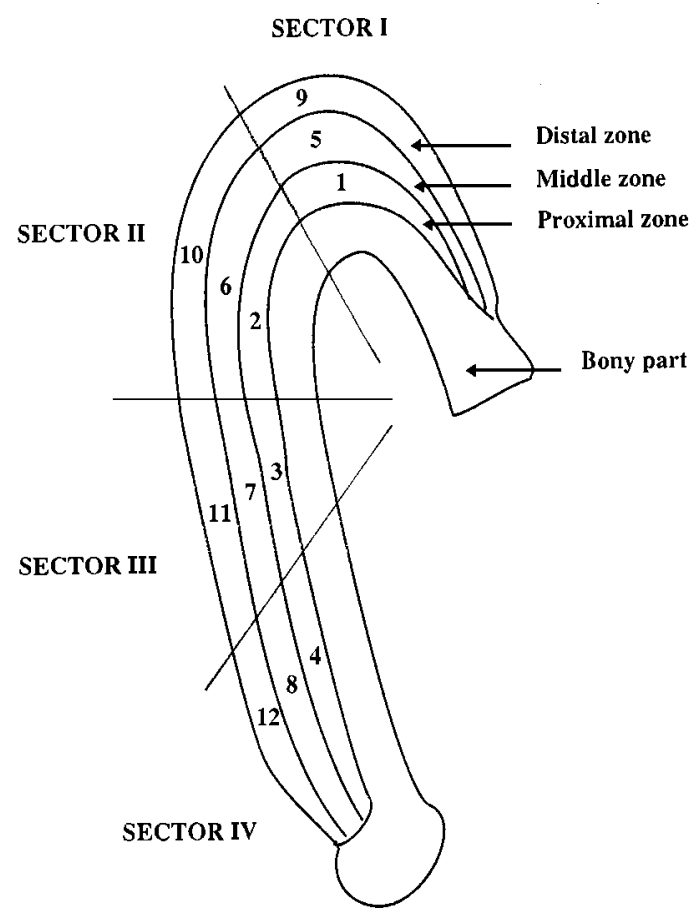

Fig. 1. Delimitation of the sectors (I to IV), zones (proximal, middle, distal) and sections (1 to 12) in a hemibranch.

\section{RESULTS}

\section{Parasite species composition}

Cephalopholis argus harboured several ectoparasite species, comprising mature and immature specimens, belonging to different groups such as monogeneans (Benedenia sp.), adult copepods (Hatschekia sp.), juvenile specimens of Caligus sp. (copepodite and chalimus larvae), and praniza larvae of the isopod Gnathia sp. Prevalence, mean intensity and the aggregation index are reported in Table 1. These data revealed no dominance of any one species over the others. Prevalence for all parasites was less than $50 \%$. The mean number of parasites of each species per infected fish was less than 6. Parasites of each species in the host population were aggregated with high variance/ mean ratio, with the exception of Gnathia sp.

Copepodite larval stages of Caligus sp. were the most common parasite with a maximum intensity of 23 parasites per fish. These parasite larvae were also the most highly aggregated among hosts (Table 1). Other parasite species or stages were rare at less than 10 parasites per fish.

\section{Microhabitat selection}

Among all parasite species found on C. argus, only the copepod Hatschekia sp. and the chalimus stage of Caligus sp. showed a preference for either the left or the right gill arches (Student's $t$-test, $\mathrm{p}<0.05$ ). Therefore, 
Table 1. Prevalence, mean intensities and variance to mean ratio (aggregation index) of different species of ectoparasites inhabiting the gills of Cephalopholis argus $(\mathrm{n}=121$ fish).

\begin{tabular}{|l|c|c|c|}
\hline Parasite species & Prevalence (\%) & Mean intensity \pm SD & Variance/mean \\
\hline Benedenia sp. & 43.8 & $2.9 \pm 2.1$ & 3.57 \\
Hatschekia sp. & 42.1 & $3.1 \pm 2.3$ & 3.97 \\
Caligus sp. copepodites & 48.8 & $5.5 \pm 4.6$ & 7.9 \\
Caligus sp. chalimus & 36.4 & $2.8 \pm 1.8$ & 3.3 \\
Gnathia sp. & 20.7 & $1.0 \pm 1.0$ & 1.3 \\
\hline
\end{tabular}

Table 2. Distribution of ectoparasites on the left gills of Cephalopholis argus. For Hatschekia sp. and chalimus stages of Caligus sp., data for left $(\mathrm{L})$ and right $(\mathrm{R})$ gills is reported because significant differences occurred.

\begin{tabular}{|c|c|c|c|c|c|c|c|c|c|c|c|c|c|}
\hline & \multicolumn{4}{|c|}{ Gill arch No. } & \multicolumn{4}{|c|}{ Sectors } & \multicolumn{3}{|c|}{ Zones } & \multirow{2}{*}{ Bony part } \\
\hline & & 1 & 2 & 3 & 4 & I & II & III & IV & Distal & Middle & Proximal & \\
\hline \multicolumn{2}{|l|}{ Benedenia sp. } & 28 & 11 & 11 & 7 & 11 & 18 & 19 & 9 & 8 & 22 & 0 & 27 \\
\hline \multirow{2}{*}{ Hatschekia sp. } & $\mathrm{L}$ & 9 & 13 & 15 & 5 & 8 & 13 & 15 & 6 & 4 & 38 & 10 & - \\
\hline & $\mathrm{R}$ & 6 & 20 & 15 & 15 & 5 & 32 & 17 & 12 & 7 & 43 & 16 & - \\
\hline $\begin{array}{l}\text { Copepodites } \\
\text { (Caligus sp.) }\end{array}$ & & 103 & 28 & 20 & 18 & 122 & 23 & 10 & 14 & 153 & 5 & 2 & 9 \\
\hline Chalimus & $\mathrm{L}$ & 10 & 15 & 40 & 0 & 56 & 6 & 3 & 0 & - & - & - & $0(15)^{*}$ \\
\hline (Caligus sp.) & $\mathrm{R}$ & 5 & 12 & 16 & 2 & 26 & 5 & 3 & 1 & - & - & - & $8(27)^{*}$ \\
\hline Praniza larvae & & 7 & 7 & 3 & 3 & 20 & 25 & 35 & 20 & 5 & 13 & 3 & - \\
\hline
\end{tabular}

* separating anterior and posterior hemibranch (in parentheses)

the number of Hatschekia sp. and chalimus stages of Caligus sp. on the left and right gill arches are reported whereas only the parasite number on the left gill arches are mentioned for the other species (Table 2).

Benedenia sp. showed a preference for the 1st gill arch (Table 2) (ANOVA and multiple comparisons, $\mathrm{p}<$ $0.005)$. However, this site selection was not confirmed for the right gill arches (ANOVA and multiple comparisons, $\mathrm{p}>0.05$ ). Benedenia sp. was more abundant on middle and bony zones of the gill arches (Table 2) (ANOVA and multiple comparisons, $\mathrm{p}<0.05$ ). No special preferences were found between gill arches and sectors (ANOVA and multiple comparisons, $p>0.05$ ).

Hatschekia sp. did not show any preference between the four left gill arches (ANOVA and multiple comparisons, $p<0.05)$. For the right gill arches, arch 3 was preferred to arches 1 and 4 (Table 2) (ANOVA and multiple comparisons, $\mathrm{p}<0.05$ ). Hatschekia $\mathrm{sp}$. was more abundant on the middle arch zones (ANOVA and multiple comparisons, $\mathrm{p}<0.05)$. No preference was found between gill arch sectors (ANOVA and multiple comparisons, $\mathrm{p}>0.05$ ).

The distribution on the gills of Caligus sp. copepodites indicated some site selection. They showed preferences for the 1st gill arch (ANOVA and multiple comparisons, $p<0.05$ ), the distal zone of the gill filaments (ANOVA and multiple comparisons, p < 0.0001 ) and sector I of the gill arches (Table 2) (ANOVA and multiple comparisons, $p<0.0001$ ). In fact, these copepodites were usually found at the extremity of the gill filaments, but sometimes some of them were found implanted by their frontal filament on the gill rakers.

Caligus sp. chalimus larvae were found exclusively on the bony part of gill arches where they preferred the anterior part (Table 2) (ANOVA and multiple comparisons, $\mathrm{p}<0.05$ ). These larvae were more abundant on the left gill arches and preferred gill arch 3 to others (Table 2) (ANOVA and multiple comparisons, p < 0.05 ). Arches 4 were favoured less by parasites and no differ-ences were found between arches 1 and 2 (ANOVA and multiple comparisons, $p>0.05$ ). The bony part of dorsal sector I of the gill arches was preferred to other less infected sectors (ANOVA and multiple comparisons, $\mathrm{p}<0.05$ ).

The praniza larvae of the isopod Gnathia sp. did not show preference for any arches, zones or sectors of the gills (ANOVA and multiple comparisons, $\mathrm{p}>0.05$ ).

\section{Interspecific associations}

Among the 121 specimens of $C$. argus sampled during our survey, $87.6 \%$ were infected by at least one parasite species or stage and $67.8 \%$ were parasitised by at least two species. Double infections were most prevalent, occurring in $40.5 \%$ of the parasitised hosts and $59.2 \%$ of these were composed of the two copepod larval stages of Caligus sp. (copepodite and chalimus). Only two individual fish harboured all the ectoparasite species: $9.1 \%$ of the hosts were infected by four parasite species; $16.5 \%$ were infected by three parasite species. 

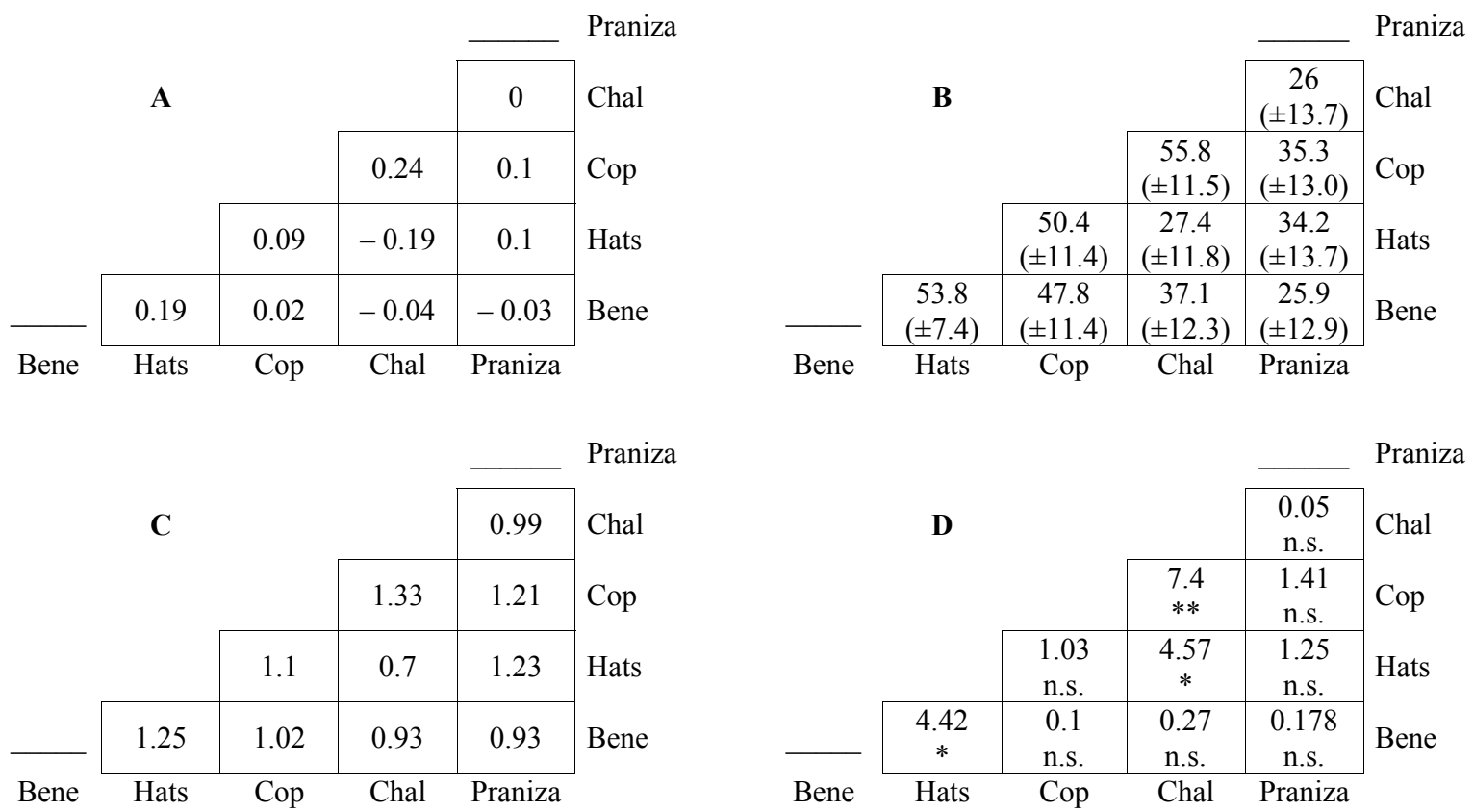

Fig. 2. Different association coefficients calculated for pairs of ectoparasite species infecting the gills of Cephalopholis argus. A - phi coefficient; B - Dice's coefficient ( \pm Standard Error at 5\% error); C - Forbes' index; D - Chi-square test and test of association. Praniza - praniza larvae Gnathia sp.; Chal - chalimus Caligus sp.; Cop - copepodite Caligus sp.; Hats Hatschekia sp.; Bene - Benedenia sp.; $:$ p $<0.05 ; * *: p<0.01 ;$ n.s. : $\mathrm{p}>0.05)$.

Chi-square $\left(\mathrm{X}^{2}\right)$ test showed a significant association between the two Caligus sp. larval stages $(\mathrm{p}<0.001)$, between Benedenia sp. and Hatschekia sp. $(\mathrm{p}<0.05)$ and between Hatschekia sp. and the chalimus stage of Caligus sp. $(\mathrm{p}<0.05)$ (Fig. 2D). The values of Dice's coefficient were high (Fig. 2B) and phi coefficients revealed two positive associations (Benedenia sp.Hatschekia sp. and copepodites-chalimus of Caligus sp.) and one negative (Hatschekia sp.-chalimus) (Fig. 2A). Forbes' index (Fig. 2C) indicated that deviations observed between these associations differ from stochastic assemblages.

\section{DISCUSSION}

\section{Microhabitat distribution and site preference}

The gill parasite community of Cephalopholis argus consisted of several stages of two crustacean species belonging to Copepoda, one species of Isopoda and one monogenean species (Capsalidae). This parasite community is characterised by the lack of a dominant species, with low prevalences (less than 50\%) and low mean intensities. The parasite species colonised most of the gill habitat with some apparent niche overlap. However, these niche overlaps were less obvious when instead of observing the fundamental niche we studied the realised niche of each parasite species (see Geets et al. 1997). Infracommunities consisted of only two parasite species compared to the five species found at the component community level.

Although some species showed preference for a particular niche, others were more site specific. Site selection and parasite distribution seemed to be highly influenced by the ability of the parasite to move freely, but also by morphological and physiological factors. Only larval stages of Caligus sp. were temporarily sessile, being attached to the gills by their frontal filament (Kabata 1981). Mobile species (Benedenia sp., Hatschekia sp. and Gnathia sp.) can move all over the gill habitat and overlapped considerably in their distribution, whereas sessile parasites seem to be more site selective.

Benedenia sp. was found on all regions of the arches from the gill filaments to the bony parts. These monogeneans were able to move easily from section to section. However, some microhabitats were preferred to others. These preferred sites were the bony zones of gill arches where $44 \%$ of Benedenia sp. were observed. One hypothesis proposed to explain this site preference may relate to the ability of Capsalidae to avoid predation (Whittington 1993, 1996). Specimens of Benedenia sp. on $C$. argus were transparent and nearly invisible to the human eye when settled on the bony zone of gill arches. Moreover, they can exhibit red pigment spots throughout the body (pers. obs.) which may serve to improve their camouflage (Whittington 1996). 
However, gill filaments were not avoided and the ability of these monogeneans to move rapidly (pers. obs.) makes them able to invade the entire gill habitat. These observations support the observations of Whittington and Kearn (1991) about the lack of site selection of these capsalids. The small mucophagous Hatschekia sp. live attached to the gill filaments using their second antennae, but are capable of moving rapidly on the gill habitat (pers. obs., Kabata 1981). Their mobility may lead to homogeneous microhabitat distribution without particular site selec-tion. The last parasite classified as freely mobile is the praniza larvae of Gnathia sp. This blood-feeding isopod is a gill parasite only during its larval stage, the adult being free-living (Kabata 1981). This parasite did not show any site preference.

Copepodite and chalimus larval stages of caligid copepods are attached to gill filaments and the bony part of gill arches respectively and consume mucus and epithelial cells (Kabata 1981). They probably represent larval stages belonging to the same adult species, which were found on the inner wall of the mouth of $C$. argus (pers. obs.). However, some unattached copepodite indi-viduals were found (pers. obs.). Their ability to detach from a substratum has been reported by Kabata and Cousens (1977), who indicated that "it is not unusual to see copepodites abandoning a half-excavated cavity and moving to another site". Observations of their distribu-tion on gill arches revealed an obvious site selection for each stage. Ninety percent of copepodite stages were located on the distal zone of filaments, mostly at their extremity (pers. obs.) and $43 \%$ of all individuals settled on dorsal sector I of gill arch 1 (Table 2). Chalimus stages inhabited exclusively the bony part, and showed same colour as the tissue on which they live, with some preference for dorsal sector I of the anterior side of gill arch 3. Microhabitat distribution of these larval stages seems to be influenced mostly by biotic factors, but the effects of abiotic factors such as respiratory current or gill arch surface should not be disregarded. For example, small copepodites were localised on arch 1 at the top of the gill filaments, whereas large chalimus were found on bony arches. Gill arch 1 is first to receive ventilating currents and appears to retain the infective larval stages even if post-settlement migration may occur. For chalimus larvae, the bony part of the gill may offer a hydrodynamically protected site.

\section{Aggregation and intraspecific interactions}

All gill parasites were aggregated among their host specimens. Some species had a restricted habitat and did not seem to avoid their congeners like the larval stages of Caligus sp. Aggregation of these parasites and site selection support Fryer's hypothesis (1966) of a "gregarious behavior" of larval parasitic crustaceans. Fryer (1966) suggested that the mechanism responsible for gregariousness might be similar to that producing colonies of sessile free-living crustaceans, i.e. a chemical attractant released by the original settler and absorbed in the substrate (Rittschof et al. 1984). Gregarious behaviour of adult male and female Caligus sp. on the palatal wall of the buccal cavity (pers. obs.) supports this hypothesis. Several authors have described the same kind of gregarious behaviour, which seems to be common for parasites belonging to the genus Caligus (e.g. Rohde 1977, 1980, 1984, 1993, Ramasamy and Ramalingam 1989, Sharples and Evans 1995).

Another hypothesis is suggested by Kabata (1981) to explain site segregation of parasitic copepods linked to the solitary behaviour of fishes. Kabata (1981) stressed that when only isolated individual host specimens are available for parasite settlement, invasion of the same host is the best way for the parasites to complete their life cycle and survive. Unfortunately, the lack of data on adult Caligus sp. in our study did not allow us to examine the relationship between larval stages and adult Caligus sp. Nevertheless, a positive association was observed between the copepodite and chalimus stages of Caligus sp., which may support the hypothesis of autoinfection.

\section{Interspecific associations and interactions}

Parasite infracommunities of $C$. argus were probably too poor to induce interspecific competition. However, some positive and negative associations were revealed. The positive association between copepodite and chalimus stages of Caligus sp. seems to be due to intraspecific mechanisms. The second positive association found was between the monogenean Benedenia sp. and the copepod Hatschekia sp. Some fish, depending on their individual characteristics (size, weight, immune system or ethology), will develop both infrapopulations. A positive association may be the result of a similar mechanism of infection in situ. No obvious reason can be suggested to explain the negative association observed between the copepod Hatschekia sp. and the chalimus stages of Caligus sp. Interspecific competition does not seem to play a role because each species occupies a different habitat (gill filaments and bony arches). We support Rohde's view (Rohde 1993) that heterogeneity within parasites (without involvement of competition) may lead to negative and positive associations. Moreover, Rohde (1993) claimed that correlations between parasite intensities and host length might lead to these associations. Indeed, positive correlations between parasite infection and host length and/or age have been revealed for some of the parasite species studied (Lo et al. 1998).

Acknowledgements. This work was part of EPHE and the University of Perpignan's programme on coral reef fish parasites in French Polynesia, with M.C. Rigby and Drs. J.C. Holmes, C. Combes, E. Faliex, C.M. Lo, S. Morand and R. 
Galzin participating. We thank Drs. P. Cabral and I.D. Whittington for their assistance in the determination of the different parasite specimens. We are grateful for the assistance of J. Algret and Dr. Y. Chancerelle. Thanks to Ingo Ernst who checked the English and provided some thoughtful comments.
C.M. Lo was supported by a grant of the Ministère de l'Education National et de la Recherche, de l'Enseignement et de la Technologie and by the Comité Economie et Gestion du Patrimoine Naturel.

\section{REFERENCES}

BUSH A.O., LAFFERTY K.D., LOTZ J.M., SHOSTAK A.W. 1997: Parasitology meets ecology on its own terms: Margolis et al. revisited. J. Parasitol. 83: 575-583.

FRYER G. 1966: Habitat selection and gregarious behaviour in parasitic crustaceans. Crustaceana 10: 192-209.

GEETS A., COENE H., OLLEVIER F. 1997: Ectoparasites of the whitespotted rabbitfish, Siganus sutor (Valenciennes, 1835) off the Kenyan Coast: distribution within the host population and site selection on the gills. Parasitology 115: 69-79.

HANEK G., FERNANDO C.H. 1978: Spatial distribution of gill parasites of Lepomis gibbosus (L.) and Ambloplites rupestris (Raf.). Can. J. Zool. 56: 1235-1240.

HOLMES J.C. 1990: Helminth communities in marine fishes. In: G.W. Esch, A.O. Bush and J.M. Aho (Eds.), Parasite Communities: Patterns and Processes. Chapman and Hall, London, New York, pp. 101-130.

KABATA Z. 1981: Copepoda (Crustacea) parasitic on fishes: problems and perspectives. In: W.H.R. Lumsden, R. Muller and J.R. Baker (Eds.), Advances in Parasitology, Vol 19. Academic Press, London, pp. 2-71.

KABATA Z., COUSENS B. 1977: Host-parasite relationships between sockeye salmon, Oncorhynchus nerka, and Salmincola californiensis (Copepoda: Lernaeopodidae). J. Fish. Res. Board Can. 34: 191-202.

KOSKIVAARA M., VALTONEN E.T., VUORI K.M. 1992: Microhabitat distribution and coexistence of Dactylogyrus species (Monogenea) on the gill of roach. Parasitology 104: 273-281.

LAMBERT A., MAILLARD C. 1974: Répartition branchiale de deux monogènes: Diplectanum aequans (Wagener 1857) Diesing, 1858 et Diplectanum lauberi Lambert et Maillard 1974 (Monogenea, Monopisthocotylea) parasites simultanés de Dicentrarchus labrax (Téléostéen). Ann. Parasitol. Hum. Comp. 50: 691-699.

LO C.M. 1998: Ecologie des parasites de poissons récifaux de l'île de Moorea (Polynésie Française). Thèse de Doctorat, Université Française du Pacifique, Papeete, Tahiti, Polynésie Française, 285 pp.

LO C.M., MORAND S. 2000: Spatial distribution and coexistence of monogenean gill parasites inhabiting two damselfishes from Moorea island in French Polynesia. J. Helminthol. (in press).

LO C.M., MORAND S., GALZIN R. 1998: Parasite diversity/ host age and size relationship in three coral reef fishes from French Polynesia. Int. J. Parasitol. 28: 1695-1708.

MALMBERG G. 1957: On the occurrence of Gyrodactylus on Swedish fish. In: Skrifterutgivna av Sodra Sveriges Fiskeriformening, pp. 19-76.

MORAND S., POULIN R., ROHDE K., HAYWARD C. 1999: Aggregation and species coexistence of ectoparasites of marine fishes. Int. J. Parasitol. 29: 663-672.
NOISY D. 1978: Recherche sur le microhabitat branchial des Microcotylidae (Monogenea) ectoparasites de Sparidae (Teleostei). Thèse de Doctorat de 3ème cycle, Université des Sciences et Techniques du Languedoc, Montpellier, France, 132 pp.

RAMASAMY P., RAMALINGAM K. 1989: The occurrence, site specificity and frequency distribution of Bicotyle vellavoli on Pampus chinensis and Pampus argenteus. Int. J. Parasitol. 19: 761-767.

RAMASAMY P., RAMALINGAM K., HANNA R.E.B., HALTON D.W. 1985: Microhabitats of gill parasites (Monogenea and Copepoda) of teleosts (Scomberoides spp.). Int. J. Parasitol. 15: 385-397.

RIGBY M.C., ADAMSON M.L. 1997: Spirocamallanus species of French Polynesian coral reef fishes. Can. J. Zool. 75: 1270-1279.

RIGBY M.C., ADAMSON M.L., DEADORFF T.L. 1998: Camallanus carangis Olsen, 1954 (Nematoda: Camallanidae) from coral reef fishes in the Pacific. J. Helminthol. Soc. Wash. 64: 227-233.

RIGBY M.C., DUFOUR V. 1996: Parasites of coral reef fish recruits, Epinephelus merra (Serranidae), in French Polynesia. J. Parasitol. 82: 405-408.

RIGBY M.C., FONT W.F. 1997: Redescription and range extension of Spirocamallanus istiblenni Noble, 1966 (Nematoda: Camallanidae) from coral reef fishes in the Pacific. J. Helminthol. Soc. Wash. 62: 227-233.

RIGBY M.C., HOLMES J.C., CRIBB T.H., MORAND S. 1997: Patterns of species diversity in the gastrointestinal helminths of a coral reef fish, Epinephelus merra (Serranidae), from French Polynesia and the South Pacific. Can. J. Zool. 75: 1818-1827.

RIGBY M.C., LO C.M., CRIBB T.H., EUZET L., FALIEX E., GALZIN R., HOLMES J.C., MORAND S. 1999: The parasites of coral reef fishes of French Polynesia: checklist and preliminary findings. Cybium 23: 273-284.

RITTSCHOF E., BRANSCOMB E.S., COSTLOW J.D. 1984: Settlement \& behaviour in relation to flow and surface in larval barnacles Balanus amphrite, Darwin. J. Exp. Mar. Biol. Ecol. 82: 131-146.

ROHDE K. 1976: Monogenean gill parasites of Scomberomorus commersoni Lacépède and other mackerel on the Australian east coast. Z. Parasitenkd. 51: 49-69.

ROHDE K. 1977: A non-competitive mechanism responsible for restricting niches. Zool. Anz. 199: 164-172.

ROHDE K. 1978a: Latitudinal gradient in species diversity and their causes. I. Marine parasitological evidence for time hypothesis. Biol. Zentralbl. 97: 405-418.

ROHDE K. 1978b: Latitudinal gradient in species diversity and their causes. II. A review of the hypotheses explaining the gradients. Biol. Zentralbl. 97: 393-403. 
ROHDE K. 1979: A critical evaluation of intrinsic and extrinsic factors responsible for niche restriction in parasites. Am. Nat. 114: 648-671.

ROHDE K. 1980: Comparative studies on microhabitat utilization by ectoparasites of some marine fishes from the North Sea and Papua New Guinea. Zool. Anz. 204: 27-63.

ROHDE K. 1984: Ecology of marine parasites. Helgol Meeresunters. 37: 5-33.

ROHDE K. 1989: Simple ecological systems, simple solution to complex problems? Evol. Theory 8: 305-350.

ROHDE K. 1991: Intra- and interspecific interactions in low density populations in resource-rich habitats. Oikos 60: 91-104.

ROHDE K. 1993: Ecology of Marine Parasites. An Introduction to Marine Parasitology. 2nd edition. $\mathrm{CAB}$ International, Wallingford, Oxon, U.K., 298 pp.

ROHDE K. 1994: Niche restriction in parasites: proximate and ultimate causes. Parasitology 109: S69-S84.

ROHDE K., HAYWARD C., HEAP M., GOSPER D. 1994: A tropical assemblage of ectoparasites: gill and head parasites of Lethrinus miniatus (Teleostei, Lethrinidae). Int. J. Parasitol. 24: 1031-1053.
ROHDE K., HEAP M. 1998: Latitudinal differences in species and community richness and in community structure of metazoan endo- and ectoparasites of marine teleost fish. Int. J. Parasitol. 28: 461-474.

SHARPLES A.D., EVANS C.W. 1995: Metazoan parasites of the snapper, Pagrus auratus (Bloch \& Schneider, 1801), in New Zealand. 2. Site-specificity. N.Z. J. Mar. Freshwater Res. 29: 203-211.

WHITTINGTON I.D. 1993: Site-specificity and camouflage in benedeniine monogeneans from Australian fishes. Proc. $2^{\text {nd }}$ Int. Symp. Monogenea, Montpellier, 101-102.

WHITTINGTON I.D. 1996: Benedeniine capsalid monogeneans from Australian fishes: pathogenic species, sitespecificity and camouflage. J. Helminthol. 70: 177-184.

WHITTINGTON I.D., KEARN G.C. 1991: The adhesive attitudes of some gill-parasitic capsalid monogeneans. J. Helminthol. 65: 280-285.

YATES F. 1934: Contingency tables involving small numbers and the C2 test. J. R. Statist. Soc. 1: 217-235. 